\title{
The Association between Dry Eye Disease and Depression, Anxiety, and Stress among Saudi Arabian Adults
}

\author{
Danah Alrajhi', Rahaf Almutairi', Basma Alturki' ${ }^{1}$, Atheer Almutairi' ${ }^{2}$, Faris Binyousef ${ }^{1}$, \\ Shahad Alruwaili ${ }^{1}$, Dalal Alessa ${ }^{3}$ \\ ${ }^{1}$ College of Medicine, Imam Mohammad Lbn Saud Islamic University, Riyadh, Saudi Arabia \\ ${ }^{2}$ Unaizah College of Medicine, Qassim University, Buraydah, Saudi Arabia \\ ${ }^{3}$ Ophthalmology Department, College of Medicine, Imam Mohammad Lbn Saud Islamic University, Riyadh, Saudi Arabia \\ Email: shahadabdullahalr@gmail.com
}

How to cite this paper: Alrajhi, D., Almutairi, R., Alturki, B., Almutairi, A., Binyousef, F., Alruwaili, S. and Alessa, D. (2021) The Association between Dry Eye Disease and Depression, Anxiety, and Stress among Saudi Arabian Adults. Open Journal of Ophthalmology, 11, 266-281.

https://doi.org/10.4236/ojoph.2021.114022

Received: September 22, 2021

Accepted: November 1, 2021

Published: November 4, 2021

Copyright $\odot 2021$ by author(s) and Scientific Research Publishing Inc. This work is licensed under the Creative Commons Attribution International License (CC BY 4.0).

http://creativecommons.org/licenses/by/4.0/

(c) (i) Open Access

\begin{abstract}
Background: Dry eye disease (DED) is a multifactorial chronic ophthalmic disease. Its symptoms include blurry vision, foreign body sensation, pain, grittiness, ocular dryness and discomfort. Multiple studies have revealed that DED has a negative impact on patients' quality of life, as well as their physical and mental health. In line with such findings, other research projects have indicated that depression, anxiety and stress share common risk factors associated with DED. Objective: We aimed to investigate the association between DED and depression, anxiety and stress among Saudi Arabian adults. Methods: This is a cross-sectional study conducted on 335 Saudi Arabian patients aimed to assess the prevalence of DED among individuals with depression, anxiety and stress. Data were collected using a self-administered questionnaire with the Depression Anxiety Stress Scales-21 (DASS-21) to assess the severity of stress, depression and anxiety, and the Ocular Surface Disease Index (OSDI) to assess DED symptoms. Results: The final number of participants was 448 . Furthermore, $72.3 \%$ of them were aged 18 - 30 years, and $69.6 \%$ of them were females. The prevalence of depression, anxiety, and stress among patients with DED was $62.1 \%, 66.1 \%, 54 \%$, and $77.9 \%$ respectively. Furthermore, we found that there were no significant differences between participants regarding the severity of DED based on different age groups $(\mathrm{P}=$ 0.889). Females with depression, anxiety, and stress, on the other hand, were significantly more likely to have severe DED than males with similar conditions. Conclusions: We confirmed a high prevalence of depression, anxiety, stress and DED in Saudi Arabian patients. There was a significant correlation between the four studied variables in which the greatest correlation was be-
\end{abstract}


tween anxiety and DED.

\section{Keywords}

Anxiety, Depression, Dry Eye Disease, Saudi Arabia

\section{Introduction}

Dry eye disease (DED) is a multifactorial chronic ophthalmic disease [1] with a global prevalence of $10 \%$ - 30\%, compared to 32.1\% in Saudi Arabia [2] [3] [4]. DED is described as a disease of the lacrimal functional unit which results in tear film instability and visual disturbance [5] [6] [7]. Its symptoms include blurry vision, a foreign body sensation, pain, grittiness, ocular dryness, and discomfort [8] [9]. Since vision is essential in a plethora of daily activities such as writing, reading, driving, watching $\mathrm{TV}$, and others, understandably, DED has a significant negative impact on patients' physical as well as mental health [10]. According to some studies, the prevalence of DED symptoms in patients suffering from depression or anxiety ranged from $21 \%$ to $52 \%$ [11]. In addition, several research studies have attested that depression, anxiety, and stress share common risk factors in association with DED, such as old age, female gender, and hormonal imbalance [8] [12] [13] [14] [15]. Moreover, the anticholinergic effect of antidepressants and anxiolytics negatively impacts tear film production, thus increasing the risk of DED in patients with these conditions [12]. Most of the studies which tackled this relationship were conducted on elderly patients and in a humid environment, preserving the integrity of the tear film and preventing quick evaporation [16] [17] [18] [19]. Therefore, we aim to investigate the association between DED and depression, anxiety and stress among DED patients in Riyadh. The results of this study may improve the knowledge of both health care providers and patients' families regarding monitoring the mental health of DED patients as well as screening for DED symptoms among patients with psychological disorders. In conclusion, this study may substantiate the need for new directions in the evaluation of DED. Furthermore, psychiatric disorders and the use of antianxiety or antidepressant medications should be considered while investigating the factors contributing to DED.

\section{Methodology}

This is a cross-sectional study conducted in Saudi Arabia from March 2021, till August 2021.Data was collected using an online questionnaire on a sample size of 335 participants as estimated by OpenEpi web tool with a 95\% confidence level. The prevalence employed to calculate this sample size was $32.1 \%$ according to a previous study [4].

Population size (for finite population correction factor or fpc) $(N): 1,000,000$, Hypothesized \% frequency of outcome factor in the population $(p): 32.1 \% \pm 5 \%$, 
Confidence limits as $\%$ of 100 (absolute $\pm \%$ ) (d): 5, Design effect (for cluster surveys-DEFF): 1 , Sample size

$n=[D E F F * N p(1-p)] /[d 2 / Z 21-\alpha / 2 *(N-1)+p *(1-p)]$.

The study included males and females aged 18 - 30 years with symptoms related to DED or psychiatric diseases such as depression, anxiety, and stress in Saudi Arabia. Participants under 18 years old were eliminated as per exclusion criteria. All participants provided informed consent and were assured that all collected data was analyzed only for scientific research purposes and would remain highly confidential. To obtain more accurate results of the questionnaire, it was validated via a pilot study on approximately 15 individuals to verify the validity of the questions along with the correctness of the language.

The questionnaire was prepared to evaluate many variables, starting with demographic variables including age, gender, marital status, educational level and occupational status. An Arabic validated version of DASS-21 was utilized in this study [21]. The Depression Anxiety Stress Scales-21 (DASS-21) questionnaire including 21 questions was used in the second section to estimate the severity of stress, depression and anxiety [20]. The questions in the last section of the questionnaire were added to assess DED by using the Ocular Surface Disease Index (OSDI) questionnaire that included12 questions [22]. According to their age in years, participants were classified into five groups " $>18,18$ - 30, 31 - 40, 41 - 50 and above 50". Educational levels were categorized as "pre-high school, high school, university, and postgraduate studies". According to their marital status, participants were classified as "single, married, divorced and widowed". To assess the occupational status, participants were provided with four fields to choose from, including "college students, employees, retired, others". Participants were asked if they have or ever had some diseases such as "diabetes, hypertension, heart disease, obesity, thyroid disease, cancer, or none of them." Participants were asked, "Have you ever been diagnosed with depression, stress, or anxiety by a physician?" In the last section of the questionnaire, participants were asked, "Have you experienced any of the following symptoms over the last week?" The symptoms inquired about were as follows: 1) light sensitivity, 2) gritty eyes, 3) sore or painful eyes, 4) blurred vision and/or poor vision. Moreover, participants were asked if their eyesight problems impeded them from performing certain activities such as reading, driving at night, working on computers, or watching TV. They were also asked if their eyes felt uncomfortable in any situation, including places with windy weather, low humidity, or air-conditioned areas over the previous week. Also, they were asked if they had ever been diagnosed with DED by a physician or not. "Have you noticed increased dryness in your eyes during periods of stress, anxiety, or depression?" was asked to assess the impact of stress, anxiety, or depression on the dryness of eyes. A statistical analysis was performed using IBM SPSS Statistics for Windows, Version 22.0 (Armonk, NY: IBM Corp). We utilized the chi-square test to attain a p-value between categorical dependent and independent data to estimate the association in which $\mathrm{p} \leq$ 
0.05 is considered significant.

\section{Results}

In this study, we received 544 responses to our questionnaire. However, after eliminating 96 participants as per the exclusion criteria (70 were under 18 years old, and 26 were not Saudi Arabian), the final number decreased to 448 with a response rate of $126 \%$. Moreover, $72.3 \%$ of them were aged 18 - 30 years old, and $69.3 \%$ of them were females. Furthermore, $69.6 \%$ were single, and $59.6 \%$ of them were university students. Considering their medical history, most participants (71.7\%) had no medical issues, while $9.1 \%$ had obesity, and the prevalence of DM was $6.6 \%$. Whereas $67.4 \%$ of them did not use any medications, and $12.7 \%$ of them indicated that they had been taking anti-depressant medications. Furthermore, our results showed that according to the participants, the prevalence of depression, anxiety and stress was $19.6 \%, 28.1 \%$ and $25.2 \%$ respectively (Table 1).

After applying the DASS-21 tool to the participants in order to determine the prevalence and severity of depression, anxiety, and stress, we found that the prevalence of depression, anxiety, and stress was $62.1 \%$ (23.7\% were extremely severe), $66.1 \%$ (30.1\% were extremely severe) and 54\% (13.2\% were extremely severe) respectively (Figure 1 ).

In the same vein, we found that according to the OSDI questionnaire, only $22.1 \%$ of participants had normal values while $49.6 \%$ of them had severe dry eyes, $17.4 \%$ had moderate dry eyes, and $10.9 \%$ had mild dry eyes (Figure 2 ).

Considering dry eye disease, $42.3 \%$ of participants reported having been diagnosed with dry eye, $35.5 \%$ of whom had been diagnosed from 1 to 5 years prior to the response to the questionnaire. Moreover, $53.8 \%$ of participants reported using lubricant eye drops, $34.8 \%$ of whom applied them once a week. Moreover, $33.5 \%$ of participants indicated that they had a family history of dry eye, and $57.5 \%$ of them did not know if there was a relation between the severity of dry eye and that of depression (Table 2).

As seen in Table 3, a significant difference between participants has been observed as the severity of depression $(P=0.000)$, anxiety $(P=0.000)$ and stress $(P$ $=0.000$ ) were conductive to the severity of DED

We found that the severity of dry eye was significantly higher in participants with more severe depression and anxiety. The participants with extremely severe depression, anxiety, and stress represented $33.3 \%, 43.7 \%$ and $20.3 \%$ of the participants with severe dry eye condition stress, while participants free of depression, anxiety, and stress represented $58.6 \%, 61.6 \%$ and $68.7 \%$ of the group with no dry eye disease. Moreover, when compared with participants with normal conditions, participants with extremely severe depression had a higher risk of having severe dry eye conditions by more than six folds $(\mathrm{OR}=6.6,95 \% \mathrm{CI}$ : 3.18:13.7, $\mathrm{P}=0.000)$ in case of severity of depression ( $\mathrm{OR}=6$, three folds in the case of moderate depression (OR: $3.23,95 \% \mathrm{CI}$ : 1.6:6.5, $\mathrm{P}=0.000$ ), and one fold 
Table 1. Demographic factors reported by participants $(\mathrm{N}=448)$.

\begin{tabular}{|c|c|c|c|}
\hline & & Frequency & $\%$ \\
\hline \multirow{4}{*}{ Age } & $18-30$ & 324 & $72.3 \%$ \\
\hline & $31-40$ & 58 & $12.9 \%$ \\
\hline & $41-50$ & 35 & $7.8 \%$ \\
\hline & Over 50 years & 31 & $6.9 \%$ \\
\hline \multirow{2}{*}{ Gender } & Male & 139 & $31.0 \%$ \\
\hline & Female & 309 & $69.0 \%$ \\
\hline \multirow{4}{*}{ Marital Status } & Single & 312 & $69.6 \%$ \\
\hline & Married & 126 & $28.1 \%$ \\
\hline & Widow & 3 & $0.7 \%$ \\
\hline & Divorced & 7 & $1.6 \%$ \\
\hline \multirow{4}{*}{ Profession } & University student & 267 & $59.6 \%$ \\
\hline & Working & 92 & $20.5 \%$ \\
\hline & Retired & 19 & $4.2 \%$ \\
\hline & Other & 70 & $15.6 \%$ \\
\hline \multirow{6}{*}{ Medical History } & No & 350 & $71.7 \%$ \\
\hline & Obesity & 44 & $9.0 \%$ \\
\hline & $\mathrm{DM}$ & 31 & $6.4 \%$ \\
\hline & Thyroid diseases & 24 & $4.9 \%$ \\
\hline & Cardiac diseases & 11 & $2.3 \%$ \\
\hline & Hypertension & 28 & $5.7 \%$ \\
\hline \multirow{7}{*}{ Used Medications } & Antihypertensive & 20 & $4.2 \%$ \\
\hline & Anti-depressant & 60 & $12.7 \%$ \\
\hline & Anti-histamine & 30 & $6.3 \%$ \\
\hline & Oral Corticosteroids & 4 & $0.8 \%$ \\
\hline & $\begin{array}{l}\text { Hormone therapy or Estrogen } \\
\text { therapy }\end{array}$ & 11 & $2.3 \%$ \\
\hline & Oral Acne therapy & 29 & $6.1 \%$ \\
\hline & Not of mentioned medications & 319 & $67.4 \%$ \\
\hline \multirow{2}{*}{$\begin{array}{c}\text { Have you ever been } \\
\text { diagnosed by depression }\end{array}$} & Yes & 88 & $19.6 \%$ \\
\hline & No & 360 & $80.4 \%$ \\
\hline \multirow{2}{*}{$\begin{array}{l}\text { Have you ever been } \\
\text { diagnosed by stress }\end{array}$} & Yes & 113 & $25.2 \%$ \\
\hline & No & 335 & $74.8 \%$ \\
\hline \multirow{2}{*}{$\begin{array}{l}\text { Have you ever been } \\
\text { diagnosed by anxiety }\end{array}$} & Yes & 126 & $28.1 \%$ \\
\hline & No & 322 & $71.9 \%$ \\
\hline
\end{tabular}




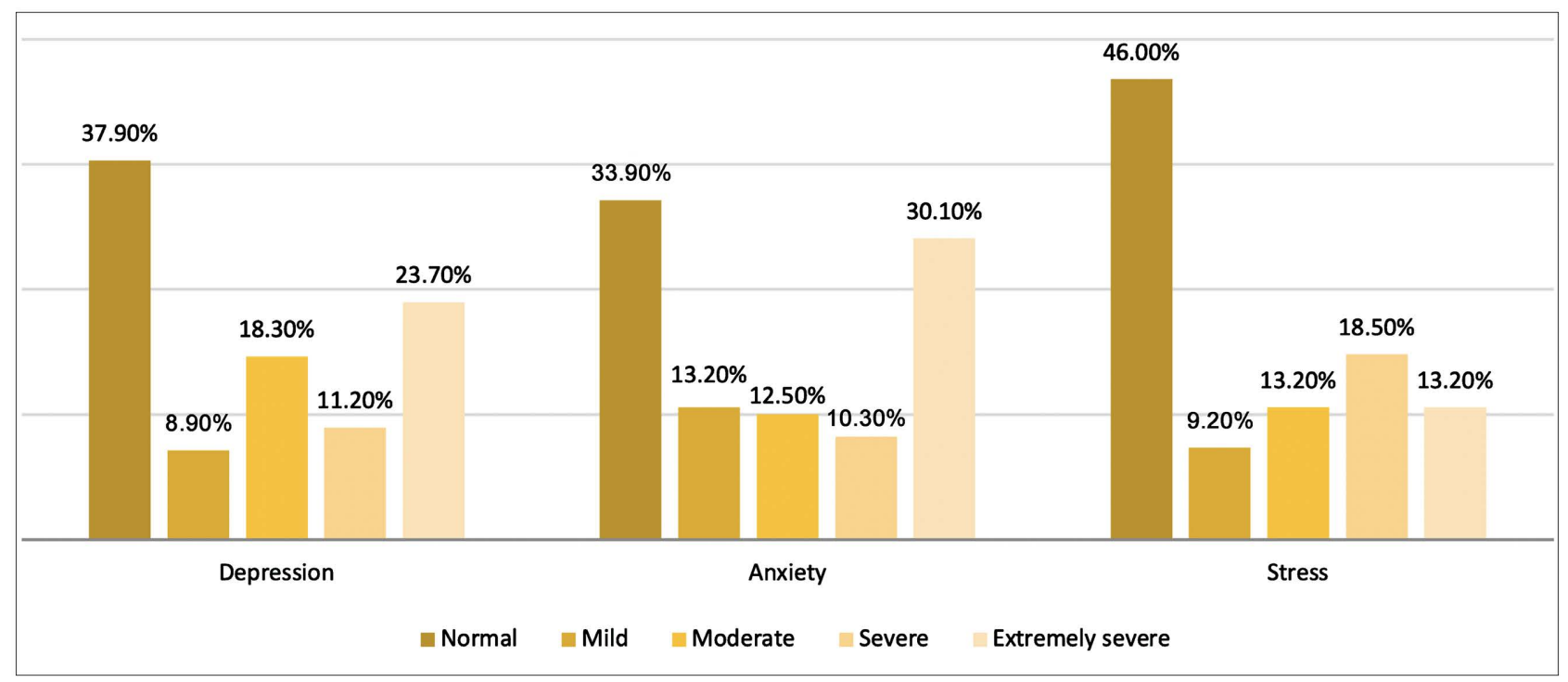

Figure 1. Distribution of severity of depression, anxiety and stress. The prevalence was calculated using DASS21 where normal mean has no depression, anxiety or stress while mild, moderate, severe, and extremely severe describe the severity of disease.

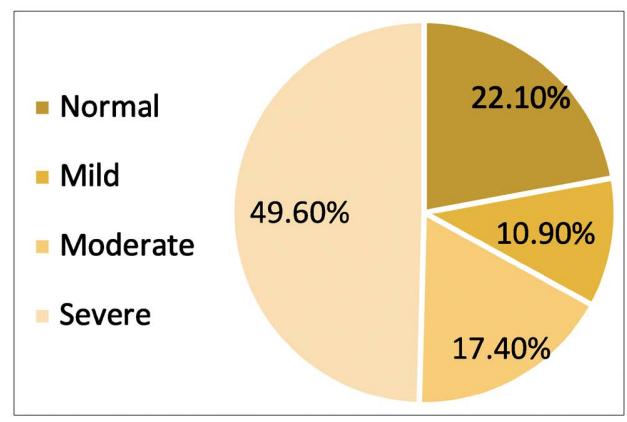

Figure 2. Prevalence and distribution of severity of Dry Eye Disease calculated using Ocular Surface Disease Index (OSDI) in which normal mean has no DED while mild, moderate and severe describe the severity of disease.

in the case of mild depression (OR:1.1, 95\% CI: 0.43: 2.6, P = 0.000). Furthermore, participants with extremely severe anxiety were 24 times vulnerable to developing severe dry eye condition (OR: 24.6, 95\% CI: 9.8: 61, P = 0.000). Also, participants with extremely stress had a higher risk for developing of severe dry eye by 6.5 times (OR: 6.47, 95\% CI: 2.7: 15.2, P = 0.000) (Table 3).

Moreover, a significant positive correlation has been noticed between depression, anxiety, and stress and the severity of the dry eye condition. In Table 4, the severity of DED is more related to anxiety than to stress or depression. Moreover, there is a positive correlation between depression, anxiety and stress.

Furthermore, there was no significant difference between participants regarding the severity of DED based on different age categories $(\mathrm{P}=0.889)$ while females were significantly related to more severe DED than males, as females represented $76.1 \%$ of severe DED compared with $55.6 \%$ of normal populations ( $\mathrm{P}$ $=0.000$ ). Moreover, there is no difference between participants regarding the severity of DED depending on marital status or profession (Table 5). 
Table 2. Practice, thoughts and diagnosis of participants toward DED.

\begin{tabular}{|c|c|c|c|}
\hline & & Frequency & Percent \% \\
\hline \multirow{2}{*}{$\begin{array}{l}\text { Have you ever been diagnosed with dry eye } \\
\text { disease? }\end{array}$} & Yes & 188 & $42.3 \%$ \\
\hline & No & 256 & $57.7 \%$ \\
\hline \multirow{4}{*}{$\begin{array}{l}\text { When you had been diagnosed with dry } \\
\text { eye disease or having symptoms of DED? } \\
(\mathrm{N}=214)\end{array}$} & Last 6 months & 33 & $15.4 \%$ \\
\hline & during the last year & 53 & $24.8 \%$ \\
\hline & From 1 to 5 years age & 76 & $35.5 \%$ \\
\hline & From more than 5 years ago & 52 & $24.3 \%$ \\
\hline \multirow[t]{2}{*}{ Do you use lubricant eye drops? } & Yes & 234 & $53.8 \%$ \\
\hline & No & 201 & $46.2 \%$ \\
\hline \multirow{4}{*}{$\begin{array}{l}\text { How often have you applied lubricant eye } \\
\text { drop? }(\mathrm{N}=230)\end{array}$} & Daily & 72 & $31.3 \%$ \\
\hline & 5 - 6 times weekly & 12 & $5.2 \%$ \\
\hline & 2 - 4 times weekly & 66 & $28.7 \%$ \\
\hline & once weekly & 80 & $34.8 \%$ \\
\hline \multirow{2}{*}{$\begin{array}{l}\text { Do you have a family history of dry eye } \\
\text { disease? }\end{array}$} & Yes & 150 & $33.5 \%$ \\
\hline & No & 298 & $66.5 \%$ \\
\hline \multirow{3}{*}{$\begin{array}{l}\text { Do you notice an increase in severity of eye } \\
\text { dryness when you experience depression } \\
\text { or anxiety }\end{array}$} & Yes & 100 & $22.3 \%$ \\
\hline & No & 91 & $20.3 \%$ \\
\hline & I do not know & 257 & $57.4 \%$ \\
\hline
\end{tabular}

Table 3. The effect of depression, anxiety and stress on the severity of DED according to OSDI.

\begin{tabular}{|c|c|c|c|c|c|c|}
\hline & \multicolumn{5}{|c|}{ OSDI } \\
\hline & & Normal & Mild & Moderate & Severe & P-value \\
\hline \multirow{5}{*}{ Depression } & Normal & $58(58.6 \%)$ & $21(42.9 \%)$ & $32(41.0 \%)$ & $59(26.6 \%)$ & \multirow{5}{*}{$0.000^{\star}$} \\
\hline & Mild & $11(11.1 \%)$ & $8(16.3 \%)$ & $9(11.5 \%)$ & $12(5.4 \%)$ & \\
\hline & Moderate & $14(14.1 \%)$ & $7(14.3 \%)$ & $15(19.2 \%)$ & $46(20.7 \%)$ & \\
\hline & Severe & $5(5.1 \%)$ & $6(12.2 \%)$ & $8(10.3 \%)$ & $31(14.0 \%)$ & \\
\hline & Extremely severe & $11(11.1 \%)$ & $7(14.3 \%)$ & $14(17.9 \%)$ & $74(33.3 \%)$ & \\
\hline \multirow{5}{*}{ Anxiety } & Normal & $61(61.6 \%)$ & $26(53.1 \%)$ & $25(32.1 \%)$ & $40(18.0 \%)$ & \multirow{5}{*}{$0.000^{*}$} \\
\hline & Mild & $13(13.1 \%)$ & $6(12.2 \%)$ & $16(20.5 \%)$ & $24(10.8 \%)$ & \\
\hline & Moderate & $10(10.1 \%)$ & $3(6.1 \%)$ & $12(15.4 \%)$ & $3(14.0 \%)$ & \\
\hline & Severe & $9(9.1 \%)$ & $1(2.0 \%)$ & $6(7.7 \%)$ & $30(13.5 \%)$ & \\
\hline & Extremely severe & $6(6.1 \%)$ & $13(26.5 \%)$ & $19(24.4 \%)$ & $97(43.7 \%)$ & \\
\hline \multirow{5}{*}{ Stress } & Normal & $68(68.7 \%)$ & $31(63.3 \%)$ & $39(50.0 \%)$ & $68(30.6 \%)$ & \multirow{5}{*}{$0.000^{*}$} \\
\hline & Mild & $6(6.1 \%)$ & $1(2.0 \%)$ & $12(15.4 \%)$ & $22(9.9 \%)$ & \\
\hline & Moderate & $10(10.1 \%)$ & $6(12.2 \%)$ & $12(15.4 \%)$ & $31(14.0 \%)$ & \\
\hline & Severe & $8(8.1 \%)$ & $8(16.3 \%)$ & $11(14.1 \%)$ & $56(25.2 \%)$ & \\
\hline & Extremely severe & $7(7.1 \%)$ & $3(6.1 \%)$ & $4(5.1 \%)$ & $45(20.3 \%)$ & \\
\hline
\end{tabular}

*significant at $\mathrm{p}$ value $\leq 0.05$. 
Table 4. Correlation between depression, anxiety, stress and DED.

\begin{tabular}{cccccc}
\hline & & Depression & Anxiety & Stress & OSDI \\
\hline \multirow{2}{*}{ Depression } & Correlation Coefficient & 1.000 & $0.710^{\star *}$ & $0.788^{* *}$ & $0.313^{\star *}$ \\
& Sig. & 0.000 & 0.000 & 0.000 & 0.000 \\
\hline \multirow{2}{*}{ Anxiety } & Correlation Coefficient & $0.710^{* *}$ & 1.000 & $0.766^{* *}$ & $0.420^{* *}$ \\
& Sig. & 0.000 & 0.000 & 0.000 & 0.000 \\
\hline \multirow{2}{*}{ Stress } & Correlation Coefficient & $0.788^{* *}$ & $0.766^{* *}$ & 1.000 & $0.338^{\star *}$ \\
& Sig. & 0.000 & 0.000 & 0.000 & 0.000 \\
\hline \multirow{2}{*}{ DED severity } & Correlation Coefficient & $0.313^{* *}$ & $0.420^{* *}$ & $0.338^{* *}$ & 1.000 \\
& Sig. & 0.000 & 0.000 & 0.000 & 0.000 \\
\hline
\end{tabular}

*significant at $\mathrm{p}$ value $\leq 0.05$.

Table 5. Demographic factors of participants and severity of DED according to OSDI.

\begin{tabular}{|c|c|c|c|c|c|c|}
\hline & & \multicolumn{4}{|c|}{ OSDI } & \multirow{2}{*}{$P$-value } \\
\hline & & Normal & Mild & Moderate & Severe & \\
\hline \multirow{4}{*}{ Age } & $18-30$ & $73(73.7 \%)$ & $37(75.5 \%)$ & $58(74.4 \%)$ & $156(70.3 \%)$ & \multirow{4}{*}{0.889} \\
\hline & $31-40$ & $14(14.1 \%)$ & $7(14.3 \%)$ & $8(10.3 \%)$ & $29(13.1 \%)$ & \\
\hline & $41-50$ & $5(5.1 \%)$ & $4(8.2 \%)$ & $7(9.0 \%)$ & $19(8.6 \%)$ & \\
\hline & $>50$ & $7(7.1 \% 0$ & $1(2.0 \%)$ & $5(6.4 \%)$ & $18(8.1 \%)$ & \\
\hline \multirow{2}{*}{ Gender } & Male & $44(44.4 \%)$ & $21(42.9 \%)$ & $21(26.9 \%)$ & $53(23.9 \%)$ & \multirow{2}{*}{$0.001^{*}$} \\
\hline & Female & $55(55.6 \%)$ & $28(57.1 \%)$ & $57(73.1 \%)$ & $169(76.1 \%)$ & \\
\hline \multirow{4}{*}{$\begin{array}{c}\text { Marital } \\
\text { status }\end{array}$} & Single & $74(74.7 \%)$ & $36(73.5 \%)$ & $51(65.4 \%)$ & $151(68.0 \%)$ & \multirow{4}{*}{0.385} \\
\hline & Married & $24(24.2 \%)$ & $13(26.5 \%)$ & $27(34.6 \%)$ & $62(27.9 \%)$ & \\
\hline & Widow & $0(0.0 \%)$ & $0(0.0 \%)$ & $0(0.0 \%)$ & $3(1.4 \%)$ & \\
\hline & Divorced & $1(1.0 \%)$ & $0(0.0 \%)$ & $0(0.0 \%)$ & $6(2.7 \%)$ & \\
\hline \multirow{4}{*}{ Profession } & $\begin{array}{c}\text { University } \\
\text { student }\end{array}$ & $61(61 \%)$ & $31(63.3 \%)$ & $50(64.1 \%)$ & $125(56.3 \%)$ & \multirow{4}{*}{0.447} \\
\hline & Working & $23(23.2 \%)$ & $10(20.4 \%)$ & $16(20.5 \%)$ & $43(19.4 \%)$ & \\
\hline & Retired & $4(4.0 \%)$ & $0(0.0 \%)$ & $4(5.1 \%)$ & $11(5.0 \%)$ & \\
\hline & Other & $11(11.1 \%)$ & $8(16.3 \%)$ & $8(10.3 \%)$ & $43(19.4 \%)$ & \\
\hline
\end{tabular}

${ }^{*}$ significant at $\mathrm{p}$ value $\leq 0.05$.

\section{Discussion}

The aim of this study was to investigate the association between DED and depression, anxiety and stress among Saudi Arabian adults. This is, to the best of our knowledge, the first study to examine the relationship between those three psychological conditions and the severity of the DED. We investigated in this study, 544 Saudi Arabians using DASS-21 to assess the level of depression, an- 
xiety, and stress, and OSDI to assess DED symptoms.

The first important issue in our study was the difference between the reported versus the investigated prevalence of depression, anxiety, stress and DED. Our results indicated that participants' reported prevalence of depression, anxiety and stress were $19.6 \%, 28.1 \%$ and $25.2 \%$ respectively. However, after applying the DASS-21 tool, we found that the prevalence of depression, anxiety, and stress was $62.1 \%, 66.1 \%$, and $54 \%$ respectively. These results showed that the majority of participants had symptoms of mental conditions, yet most of them were not diagnosed with these conditions. According to the study of A. Ahmed, the prevalence of depression, anxiety and stress among dermatology patients in Saudi Arabia was $12.6 \%, 22.1 \%$ and $7.5 \%$ respectively [23], and these findings are consistent with ours in that anxiety is the most common mental condition in our society. Moreover, M Mukrim showed better results than ours as hepostulated that the prevalence of depression, anxiety and stress in Northern Saudi Arabia using DASS-21 tools was 37.4\%, 45.6\% and $18.7 \%$ [4]. The high prevalence of depression, anxiety, and stress in our results-compared to the prevalence concluded by the previous studies conducted in Saudi Arabia-may be related to the current situation of the COVID-19 pandemic, as several studies have documented that the pandemic is associated with an increased prevalence of different psychological conditions among the populations [24] [25] [26].

Furthermore, we discovered that $77.9 \%$ of participants had DED, with $49.6 \%$ having severe dry eyes, $17.4 \%$ having moderate dry eyes, and $10.9 \%$ having mild dry eyes, according to the OSDI tool. This prevalence is higher than that reported by the study of Y Shanti in Palestine in which the prevalence of DED was $64 \%$ [27], the research study of J Hyon on medical students reporting a DED prevalence of $27.1 \%$ [28] and that of Kofi Asiedu who reported a prevalence of $49.7 \%$ where $20 \%$ had severe DED, $7.5 \%$ had moderate DED and $22 \%$ had mild DED [29]. In Saudi Arabia, the prevalence of DED was $30 \%$ in the study of $Z$. Yasir [30] and 75\% in the study of Alhamyani [31]. Furthermore, we discovered that females were more affected by DED than males, with females accounting for 76.1 percent of the severe DED compared to 55.6 percent of the normal population.This finding agrees with other studies, including the study of Z. Yasir in which the prevalence of DED among females was significantly higher than among males [30] as well as the studies of Alshamrani in Jeddah [32] and that of A. Bukhari in Al-Ahsa, Saudi Arabia [33]. The higher prevalence and severity of DED reported in this study among females compared with males can be explained in light of the social characteristics of Saudi Arabia, where females generally remain indoors for a longer time period compared to men. Therefore, females spend more time in air-conditioned environments and use computers and smartphones more than males [30]. Another explanation could be the female hormone, which has been identified as a risk factor for DED [34]. On the other hand, other studies reported inconsistent findings with ours, such as the study of Alhamyani, who reported that the prevalence of DED was 
not different depending on gender [31], and the study of Titiyal et al., who contended that males had higher DED rates than females [35]. Moreover, we did not observe a difference between participants regarding DED depending on age differences. This finding backs up the findings of previous studies [31] [35]. Other studies, however, have found that the severity and prevalence of DED increase with age [27] [32].

Furthermore, we observed a significant positive correlation between the severity of DED and that of depression, anxiety and stress. Anxiety, the most common condition among Saudi Arabians, is the associated risk factor of DED in which participants with extremely severe anxiety have a 24 time higher risk of developing severe DED compared to those with depression (six times) and those with stress (6.5\%) when compared with normal populations. Many previous studies have confirmed a significant correlation between DED, depression, anxiety, and stress [36] [37] [38] [39]. According to previous literature, the relationship seemed to start either way, as DED plays a role in experiencing depression and vice versa [17]. According to Wang et al., patients with DED were more likely to have depression (OR 2.11) [19]. This relation between depression and dry eye can be explained as dry eye symptoms may increase depression symptoms or antidepressant medications affect the anticholinergic activity [40]. This relationship between depression, anxiety, stress and DED signifies the importance of detecting each disease among individuals with another condition, mainly to track anxiety in individuals with DED.

This study has some limitations that might have affected the accuracy of the findings. The first limitation was using social media to collect responses. Therefore, most participants were mainly from a young age group. However, we used a validated questionnaire to evaluate all variables; these scales were aimed at screening rather than diagnosing. Thus, they may have overestimated the real prevalence. Moreover, an ophthalmologic examination for dry eye signs and symptoms was not performed. So far, an examination of the ocular surface, the tear film, and dry eye symptoms, has been mandatory for the definitive diagnosis of DED, yet we did not perform an ophthalmologic examination. Therefore, there was a possibility that patients with ocular surface diseases other than DED dry eye symptoms were included. Furthermore, participants may have been untruthful and had biases that could not be excluded.

\section{Conclusion}

We found a high prevalence of depression, anxiety, stress, and DED in Saudi Arabia. There is a significant correlation between the four variables studied, with anxiety and DED having the strongest correlation.

Further investigations should be conducted involving a clinical examination of dry eye signs. We recommend screening for depression among patients diagnosed with DED in ophthalmology clinics as well as primary care clinics as a proactive measure to improve life quality and preserve psychological well-being. 


\section{Conflicts of Interest}

The authors declare no conflicts of interest regarding the publication of this paper.

\section{References}

[1] The Ocular Surface (2007) The Epidemiology of Dry Eye Disease: Report of the Epidemiology Subcommittee of the International Dry Eye WorkShop. The Ocular Surface, 5, 93-107. https://doi.org/10.1016/S1542-0124(12)70082-4

[2] Lin, P.Y., Tsai, S.Y., Cheng, C.Y., Liu, J.H., Chou, P. and Hsu, W.M. (2003) Prevalence of Dry Eye among an Elderly Chinese Population in Taiwan. Ophthalmology, 110, 1096-1101. https://doi.org/10.1016/S0161-6420(03)00262-8

[3] Han, S.B. (2011) Prevalence of Dry Eye Disease in an Elderly Korean Population. Archives of Ophthalmology, 129, 633-638. https://doi.org/10.1001/archophthalmol.2011.78

[4] Mukrim, A., Alshammari, N., Alshammari, W., et al. (2019) Prevalence of Depression, Anxiety and Stress among Diabetes Mellitus Patients in Arar, Northern Saudi Arabia. International Journal of Medicine in Developing Countries, 3, 229-233. https://doi.org/10.24911/IJMDC.51-1542576396

[5] The Ocular Surface (2007) Management and Therapy of Dry Eye Disease: Report of the Management and Therapy Subcommittee of the International Dry Eye WorkShop. The Ocular Surface, 5, 163-178. https://doi.org/10.1016/S1542-0124(12)70085-X

[6] Stern, M.E., Beuerman, R.W., Fox, R.I., Gao, J., Mircheff, A.K. and Pflugfelder, S.C. (1998) The Pathology of Dry Eye. Cornea, 17, 584. https://doi.org/10.1097/00003226-199811000-00002

[7] The Ocular Surface. (2007) The Definition and Classification of Dry Eye Disease: Report of the Definition and Classification Subcommittee of the International Dry Eye Workshop. The Ocular Surface, 5, 75-92. https://doi.org/10.1016/S1542-0124(12)70081-2

[8] Miljanović, B., Trivedi, K.A., Dana, M.R., Gilbard, J.P., Buring, J.E. and Schaumberg, D.A. (2005) Relation between Dietary n-3 and n-6 Fatty Acids and Clinically Diagnosed Dry Eye Syndrome in Women. The American Journal of Clinical Nutrition, 82, 887-893. https://doi.org/10.1093/ajcn/82.4.887

[9] Uchino, M., Schaumberg, D.A., Dogru, M., et al. (2008) Prevalence of Dry Eye Disease among Japanese Visual Display Terminal Users. Ophthalmology, 115, 1982 1988. https://doi.org/10.1016/j.ophtha.2008.06.022

[10] Miljanović, B., Dana, R., Sullivan, D.A. and Schaumberg, D.A. (2007) Impact of Dry Eye Syndrome on Vision-Related Quality of Life. American Journal of Ophthalmology, 143, 409-415. https://doi.org/10.1016/j.ajo.2006.11.060

[11] Ulusoy, M.O., Işık-Ulusoy, S. and Kıvanç, S.A. (2019) Evaluation of Dry Eye Disease in Newly Diagnosed Anxiety and Depression Patients Using Anterior Segment Optical Coherence Tomography. Eye and Vision, 6, Article No. 25. https://doi.org/10.1186/s40662-019-0149-y

[12] Wen, W., Wu, Y., Chen, Y., et al. (2012) Dry Eye Disease in Patients With Depressive and Anxiety Disorders in Shanghai. Cornea, 31, 686-692. https://doi.org/10.1097/ICO.0b013e3182261590

[13] van der Vaart, R., Weaver, M.A., Lefebvre, C. and Davis, R.M. (2015) The Association between Dry Eye Disease and Depression and Anxiety in a Large Population- 
Based Study. American Journal of Ophthalmology, 159, 470-474. https://doi.org/10.1016/j.ajo.2014.11.028

[14] Labbé, A., Wang, Y.X., Jie, Y., Baudouin, C., Jonas, J.B. and Xu, L. (2013) Dry Eye Disease, Dry Eye Symptoms and Depression: The Beijing Eye Study. British Journal of Ophthalmology, 97, 1399-1403. https://doi.org/10.1136/bjophthalmol-2013-303838

[15] Na, K.S., Han, K., Park, Y.G., Na, C. and Joo, C.K. (2015) Depression, Stress, Quality of Life, and Dry Eye Disease in Korean Women. Cornea, 34, 733-738. https://doi.org/10.1097/ICO.0000000000000464

[16] Kim, K.W., Han, S.B., Han, E.R., et al. (2011) Association between Depression and Dry Eye Disease in an Elderly Population. Investigative Opthalmology \& Visual Science, 52, 7954-7958. https://doi.org/10.1167/iovs.11-8050

[17] Lemp, M.A. (2008) Advances in Understanding and Managing Dry Eye Disease. American Journal of Ophthalmology, 146, 350-356. https://doi.org/10.1016/j.ajo.2008.05.016

[18] Schaumberg, D.A. (2009) Prevalence of Dry Eye Disease among US Men. Archives of Ophthalmology, 127, 763-768. https://doi.org/10.1001/archophthalmol.2009.103

[19] Wang, T.J., Wang, I.J., Hu, C.C. and Lin, H.C. (2012) Comorbidities of Dry Eye Disease: A Nationwide Population-Based Study. Acta Ophthalmologica, 90, 663-668. https://doi.org/10.1111/j.1755-3768.2010.01993.x

[20] Antony, M.M., Bieling, P.J., Cox, B.J., Enns, M.W. and Swinson, R.P. (1998) Psychometric Properties of the 42-Item and 21-Item Versions of the Depression Anxiety Stress Scales in Clinical Groups and a Community Sample. Psychological As sessment, 10, 176-181. https://doi.org/10.1037/1040-3590.10.2.176

[21] Moussa, M.T., Lovibond, P., Laube, R. and Megahead, H.A. (2017) Psychometric Properties of an Arabic Version of the Depression Anxiety Stress Scales (DASS). Research on Social Work Practice, 27, 375-386. https://doi.org/10.1177/1049731516662916

[22] Schiffman, R.M. (2000) Reliability and Validity of the Ocular Surface Disease Index. Archives of Ophthalmology, 118, 615-621. https://doi.org/10.1001/archopht.118.5.615

[23] Ahmed, A.E., Al-Dahmash, A.M., Al-Boqami, Q.T. and Al-Tebainawi, Y.F. (2016) Depression, Anxiety and Stress among Saudi Arabian Dermatology Patients: CrossSectional Study. Sultan Qaboos University Medical Journal, 16, 217-223. https://doi.org/10.18295/squmj.2016.16.02.013

[24] Gao, J., Zheng, P., Jia, Y., et al. (2020) Mental Health Problems and Social Media Exposure during COVID-19 Outbreak. PLoS ONE, 15, e0231924. https://doi.org/10.1371/journal.pone.0231924

[25] Pfefferbaum, B. and North, C.S. (2020) Mental Health and the Covid-19 Pandemic. New England Journal of Medicine, 383, 510-512. https://doi.org/10.1056/NEJMp2008017

[26] Qiu, J., Shen, B., Zhao, M., Wang, Z., Xie, B. and Xu, Y. (2020) A Nationwide Survey of Psychological Distress among Chinese People in the COVID-19 Epidemic: Implications and Policy Recommendations. General Psychiatry, 33, e100213. https://doi.org/10.1136/gpsych-2020-100213

[27] Shanti, Y., Shehada, R., Bakkar, M.M. and Qaddumi, J. (2020) Prevalence and Associated Risk Factors of Dry Eye Disease in 16 Northern West Bank Towns in Palestine: A Cross-Sectional Study. BMC Ophthalmology, 20, Article No. 26. https://doi.org/10.1186/s12886-019-1290-Z 
[28] Hyon, J.Y., Yang, H.K. and Han, S.B. (2019) Dry Eye Symptoms May Have Association With Psychological Stress in Medical Students. Eye \& Contact Lens. Science \& Clinical Practice, 45, 310-314. https://doi.org/10.1097/ICL.0000000000000567

[29] Asiedu, K., Dzasimatu, S.K. and Kyei, S. (2018) Impact of Dry Eye on Psychosomatic Symptoms and Quality of Life in a Healthy Youthful Clinical Sample. Eye \& Contact Lens: Science \& Clinical Practice, 44, S404-S409.

https://doi.org/10.1097/ICL.0000000000000550

[30] Yasir, Z., Chauhan, D., Khandekar, R., Souru, C. and Varghese, S. (2019) Prevalence and Determinants of Dry Eye Disease among 40 Years and Older Population of Riyadh (Except Capital), Saudi Arabia. Middle East African Journal of Ophthalmolo$g y$, 26, 27-32. https://doi.org/10.4103/meajo.MEAJO 19418

[31] Alhamyani, A., Noor Kalakattawi, R., Noor Kalakattawi, A., et al. (2017) Prevalence of Dry Eye Symptoms and Its Risk Factors among Patients of King Abdulaziz Specialist Hospital (Taif), Saudi Arabia. Saudi Journal for Health Sciences, 6, 140-144. https://doi.org/10.4103/sjhs.sjhs $90 \quad 17$

[32] Alshamrani, A., Almousa, A., Almulhim, A., et al. (2017) Prevalence and Risk Factors of Dry Eye Symptoms in a Saudi Arabian Population. Middle East African Journal of Ophthalmology, 24, 67-73. https://doi.org/10.4103/meajo.MEAJO $281 \quad 16$

[33] Bukhari, A., Ajlan, R. and Alsaggaf, H. (2009) Prevalence of Dry Eye in the Normal Population in Jeddah, Saudi Arabia. Orbit, 28, 392-397. https://doi.org/10.3109/01676830903074095

[34] Vehof, J., Sillevis Smitt-Kamminga, N., Nibourg, S.A. and Hammond, C.J. (2018) Sex Differences in Clinical Characteristics of Dry Eye Disease. The Ocular Surface, 16, 242-248. https://doi.org/10.1016/j.jtos.2018.01.001

[35] Titiyal, J.S., Falera, R.C., Kaur, M., Sharma, V. and Sharma, N. (2018) Prevalence and Risk Factors of Dry Eye Disease in North India: Ocular Surface Disease IndexBased Cross-Sectional Hospital Study. Indian J Ophthalmol, 66, 207-211.

[36] Wan, K.H., Chen, L.J. and Young, A.L. (2016) Depression and Anxiety in Dry Eye Disease: A Systematic Review and Meta-Analysis. Eye, 30, 1558-1567.

https://doi.org/10.1038/eye.2016.186

[37] Hallak, J.A., Tibrewal, S. and Jain, S. (2015) Depressive Symptoms in Patients With Dry Eye Disease. Cornea, 34, 1545-1550. https://doi.org/10.1097/ICO.0000000000000641

[38] Liyue, H., Chiang, P.C., Sung, S.C. and Tong, L. (2016) Dry Eye-Related Visual Blurring and Irritative Symptoms and Their Association with Depression and Anxiety in Eye Clinic Patients. Current Eye Research, 41, 590-599. https://doi.org/10.3109/02713683.2015.1056804

[39] Al-Dairi, W., Al Sowayigh, O.M., Alkulaib, N.S. and Alsaad, A. (2020) The Relationship of Dry Eye Disease With Depression in Saudi Arabia: A Cross-Sectional Study. Cureus, 12, e12160. https://doi.org/10.7759/cureus.12160

[40] Galor, A., Feuer, W., Lee, D.J., et al. (2012) Depression, Post-Traumatic Stress Disorder, and Dry Eye Syndrome: A Study Utilizing the National United States Veterans Affairs Administrative Database. American Journal of Ophthalmology, 154, 340 346. https://doi.org/10.1016/j.ajo.2012.02.009 
Questionnaire: The Associations between Dry Eye Disease and Depression, Anxiety, and Stress among Saudi Arabian Adults

\section{Q1. Demographics Data}

\begin{tabular}{|c|c|}
\hline \multirow{4}{*}{ Age } & $18-30$ \\
\hline & $31-40$ \\
\hline & $41-50$ \\
\hline & Over 50 years \\
\hline \multirow[t]{2}{*}{ Gender } & Male \\
\hline & Female \\
\hline \multirow[t]{4}{*}{ Marital Status } & Single \\
\hline & Married \\
\hline & Widow \\
\hline & Divorced \\
\hline \multirow[t]{4}{*}{ Profession } & University student \\
\hline & Working \\
\hline & Retired \\
\hline & Other \\
\hline \multirow[t]{6}{*}{ Medical History } & No \\
\hline & Obesity \\
\hline & $\mathrm{DM}$ \\
\hline & Thyroid diseases \\
\hline & Cardiac diseases \\
\hline & Hypertension \\
\hline \multirow[t]{7}{*}{ Used Medications } & Antihypertensive \\
\hline & Anti-depressant \\
\hline & Anti-histamine \\
\hline & Oral Corticosteroids \\
\hline & Hormone therapy or Estrogen therapy \\
\hline & Oral Acne therapy \\
\hline & Not of mentioned medications \\
\hline \multirow[t]{2}{*}{ Have you ever been diagnosed by depression } & Yes \\
\hline & No \\
\hline \multirow[t]{2}{*}{ Have you ever been diagnosed by stress } & Yes \\
\hline & No \\
\hline \multirow[t]{2}{*}{ Have you ever been diagnosed by anxiety } & Yes \\
\hline & No \\
\hline
\end{tabular}




\section{Q2. Assessment Depression, Anxiety, and Stress by Using DASS-21 Tool}

Please read each statement and circle a number $0,1,2$ or 3 which indicates how much the statement applied to you over the past week. There are no right or wrong answers. Do not spend too much time on any statement.

The rating scale is as follows:

$0 \quad$ Did not apply to me at all

1 Applied to me to some degree, or some of the time

2 Applied to me to a considerable degree or a good part of time

3 Applied to me very much or most of the time

\begin{tabular}{|c|c|c|c|c|c|}
\hline $1(\mathrm{~s})$ & I found it hard to wind down & 0 & 1 & 2 & 3 \\
\hline 2 (a) & I was aware of dryness of my mouth & 0 & 1 & 2 & 3 \\
\hline 3 (d) & I couldn't seem to experience any positive feeling at all & 0 & 1 & 2 & 3 \\
\hline 4 (a) & $\begin{array}{l}\text { I experienced breathing difficulty (e.g. excessively rapid breathing, } \\
\text { breathlessness in the absence of physical exertion) }\end{array}$ & 0 & 1 & 2 & 3 \\
\hline 5 (d) & I found it difficult to work up the initiative to do things & 0 & 1 & 2 & 3 \\
\hline $6(\mathrm{~s})$ & I tended to over-react to situations & 0 & 1 & 2 & 3 \\
\hline 7 (a) & I experienced trembling (e.g. in the hands) & 0 & 1 & 2 & 3 \\
\hline 8 (s) & I felt that I was using a lot of nervous energy & 0 & 1 & 2 & 3 \\
\hline 9 (a) & $\begin{array}{l}\text { I was worried about situations in which I might panic and make a fool } \\
\text { of myself }\end{array}$ & 0 & 1 & 2 & 3 \\
\hline 10 (d) & I felt that I had nothing to look forward to & 0 & 1 & 2 & 3 \\
\hline $11(s)$ & I found myself getting agitated & 0 & 1 & 2 & 3 \\
\hline $12(s)$ & I found it difficult to relax & 0 & 1 & 2 & 3 \\
\hline 13 (d) & I felt down-hearted and blue & 0 & 1 & 2 & 3 \\
\hline $14(s)$ & $\begin{array}{l}\text { I was intolerant of anything that kept me from getting on with what I } \\
\text { was doing }\end{array}$ & 0 & 1 & 2 & 3 \\
\hline 15 (a) & I felt I was close to panic & 0 & 1 & 2 & 3 \\
\hline 16 (d) & I was unable to become enthusiastic about anything & 0 & 1 & 2 & 3 \\
\hline 17 (d) & I felt I wasn't worth much as a person & 0 & 1 & 2 & 3 \\
\hline $18(s)$ & I felt that I was rather touchy & 0 & 1 & 2 & 3 \\
\hline 19 (a) & $\begin{array}{l}\text { I was aware of the action of my heart in the absence of physical } \\
\text { exertion (e.g. sense of heart rate increase, heart missing a beat) }\end{array}$ & 0 & 1 & 2 & 3 \\
\hline 20 (a) & I felt scared without any good reason & 0 & 1 & 2 & 3 \\
\hline 21 (d) & I felt that life was meaningless & 0 & 1 & 2 & 3 \\
\hline
\end{tabular}




\section{Q3. Assessment of DED Severity by Using OSDI Tool}

HaVe you experienced any OF the fOLlOWING dURING the LAST WeEK:

\begin{tabular}{|lcccccc|}
\hline 1. Eyes that are sensitive to light? & $\begin{array}{c}\text { All of } \\
\text { the time }\end{array}$ & $\begin{array}{c}\text { Most of } \\
\text { the time }\end{array}$ & 3 & $\begin{array}{c}\text { Half of } \\
\text { the time }\end{array}$ & $\begin{array}{c}\text { Some of } \\
\text { the time }\end{array}$ & $\begin{array}{c}\text { None of } \\
\text { the time }\end{array}$ \\
\hline 2. Eyes that feel gritty? & 4 & 3 & 2 & 1 & 0 \\
\hline 3. Painful or sore eyes? & 4 & 3 & 2 & 1 & 0 \\
\hline 4. Blurred vision? & 4 & 3 & 2 & 1 & 0 \\
\hline 5. Poor vision? & 4 & 3 & 2 & 1 & 0 \\
\hline
\end{tabular}

Subtotal score for answers 1 to 5

HAVE PROBLEMS WITH YOUR EYES LIMITED YOU IN PERFORMING ANY OF THE FOLLOWING DURING THE LAST WEEK:

\begin{tabular}{|lccccc||}
\hline & $\begin{array}{c}\text { All of } \\
\text { the time }\end{array}$ & $\begin{array}{c}\text { Most of } \\
\text { the time }\end{array}$ & $\begin{array}{c}\text { Half of } \\
\text { the time }\end{array}$ & $\begin{array}{c}\text { Some of } \\
\text { the time }\end{array}$ & $\begin{array}{c}\text { None of } \\
\text { the time }\end{array}$ \\
\hline 7. Driving at night? & 4 & 3 & 2 & 1 & 0 \\
\hline $\begin{array}{l}\text { 8. Working with a computer } \\
\text { or bank machine (ATM)? }\end{array}$ & 4 & 3 & 2 & 1 & 0 \\
\hline \begin{tabular}{l} 
9. Watching TV? \\
\hline
\end{tabular} & 4 & 3 & 2 & 1 & 0 \\
N/A \\
N/A \\
N/A \\
N/A \\
\hline
\end{tabular}

Subtotal score for answers 6 to 9

Have your eyes felt uncomfortable

IN ANY OF THE FOLLOWING SITUATIONS DURING THE LAST WEEK:

\begin{tabular}{|c|c|c|c|c|c|c|}
\hline & $\begin{array}{l}\text { All of } \\
\text { the time }\end{array}$ & $\begin{array}{l}\text { Most of } \\
\text { the time }\end{array}$ & $\begin{array}{l}\text { Half of } \\
\text { the time }\end{array}$ & $\begin{array}{l}\text { Some of } \\
\text { the time }\end{array}$ & $\begin{array}{l}\text { None of } \\
\text { the time }\end{array}$ & \\
\hline 10. Windy conditions? & 4 & 3 & 2 & 1 & 0 & N/A \\
\hline $\begin{array}{l}\text { 11. Places or areas with } \\
\text { low humidity (very dry)? }\end{array}$ & 4 & 3 & 2 & 1 & 0 & N/A \\
\hline 12. Areas that are air conditioned? & 4 & 3 & 2 & 1 & 0 & N/A \\
\hline \multicolumn{5}{|c|}{ Subtotal score for answers 10 to 12} & (C) & \\
\hline
\end{tabular}

